\title{
Особенности режима климатических характеристик скорости ветра на территории Сюникского марза
}

\author{
В.Г. Маргарян $\bowtie$ \\ Ереванский государственный университет, Республика Армения \\ (0025, г. Ереван, ул. Алека Манукяна, 1)
}

\begin{abstract}
Аннотация: Цель: Изучение особенностей режима климатических характеристик скорости ветра на территории Сюникского марза Республики Армения является актуальной задачей, особенно в связи с тем обстоятельством, что экономика Армении значительно зависит от внешних поступлений энергоносителей. А силу ветра можно использовать как источник альтернативной энергии.

В статье анализированы и оценены закономерности режима скорости ветра, их территориального и временного распределения, дневного и внутригодового хода, тенденция межгодового изменения на изучаемой территории. Также дана характеристика сильных ветров и штилей. Для анализа использованы данные «Службы по гидрометеорологии и активному воздействию на атмосферные явления» МЧС Республики Армения за период 50 лет и более (1966-2018 гг.) на 7 метеорологических станциях.

Выявлены, что на территории Сюникского марза наблюдается хорошо выраженный суточный и разнообразный годовой ход. Разнообразие годового хода скорости ветра обусловлено пересеченностью местности. Средняя годовая скорость ветра составляет 1,1-7,7 м/сек, а годовая максимальная скорость ветра - 18-48 м/сек. Наибольшие скорости ветра наблюдаются на Сисианском и Воротанском перевалах. С высотой растет скорость ветра. Получена корреляционная связь между годовыми средними значениями скорости ветра исследуемой территории и высотой места, которые можно использовать для изучения режима скорости ветра неизученных и мало изученных территорий. В марзе за период 2011-2018 гг. в основном наблюдается тенденция уменьшения скорости ветра по сравнению с периодом за 1966-1985 годы.

Выполненный анализ пространственного изменения характеристик скорости ветрового режима показал разнообразие, обусловленное пересеченностью местности, где рельеф оказывает большое влияние на распределение характеристик скорости ветра.

Полученные результаты могут быть использованы при планировании развития ветроэнергетики на территории Сюникского марза, разработке ветроэнергетических кадастров территорий, климатическом обслуживании отраслей народного хозяйства, корректировке строительных нормативов.
\end{abstract}

Ключевые слова: Армения, Сюникский марз, скорость ветра, повторяемость, штиль, глобальное изменение климата, отклонения.

Для цитирования: Маргарян В.Г. Особенности режима климатических характеристик скорости ветра на территории Сюникского марза // Вестник Воронежского государственного университета. Серия: География. Геоэкология, 2020, № 2, с. 46-54. DOI: https://doi.org/10.17308/geo.2020.2/2885

\section{ВВЕДЕНИЕ}

Ветер является одной из важнейших характеристик состояния атмосферы, ландшафтообразующих, геологических и рельефообразующих факторов на поверхности суши, оказывает механическое воздействие на почву и растительность, значительное влияние оказывает на распределение снежного покрова, загрязнение воздушного бас-

() Маргарян В.Г., 2020

$\triangle$ E-mail: vmargaryan@ysu.am сейна, на влаго- и теплообмен. Рост потребности человечества в энергетических ресурсах приводит к необходимости поиска и более широкого использования альтернативных источников энергообеспечения. К их числу относится ветроэнергетика. Ее развитие зависит от достоверной информации о режиме ветра на территории предполагаемого размещения ветроэнергетических установок. Это особенно актуально для Республики Армения,

Контент доступен под лицензией Creative Commons Attribution 4.0 License. 
Список метеостанций и метеорологических наблюдательных пунктов в Сюникском марзе

(в скобках указана дата перевода, из-за которого была нарушена однородность ряда, * - с года работы метеорологических наблюдательных пунктов)

[Table 1. List of meteorological stations and meteorological observation posts in the Syunik marz area (the date of the transfer is indicated in brackets, due to which the uniformity of the series was violated, * - from the year the meteorological observation posts were open)]

\begin{tabular}{|c|c|c|c|c|c|}
\hline $\begin{array}{l}\text { Имя / } \\
\text { Name }\end{array}$ & $\begin{array}{l}\text { Высота, м / } \\
\text { Height, m }\end{array}$ & $\begin{array}{c}\text { Срок наблюдений / } \\
\text { Observation period }\end{array}$ & $\begin{array}{l}\text { Имя / } \\
\text { Name }\end{array}$ & $\begin{array}{l}\text { Высота, м / } \\
\text { Height, m }\end{array}$ & $\begin{array}{l}\text { Срок наблюдений / } \\
\text { Observation period }\end{array}$ \\
\hline $\begin{array}{l}\text { Воротанский } \\
\text { перевал }\end{array}$ & 2387 & $1961-2018$ & Аревис & 1950 & $1969-89 *$ \\
\hline Горайк & 2014 & 1933-64; 1965-75* & Дастакерт & 1900 & $1949-88^{*}$ \\
\hline Сарнакунк & 2090 & 1953-64* & Татев & 1580 & $1958-78 *$ \\
\hline Цхук & 2023 & $1978-2002 *$ & Давид Бек & 850 & $1932-37 *$ \\
\hline Ангехакот & 1834 & $1933-95^{*}$ & Хотанан В. & 1406 & 1948-75; 1976-88* \\
\hline Tex & 1335 & $1932-75^{*}$ & Кирс & 2108 & 1957-88* \\
\hline $\begin{array}{l}\text { Сисианский } \\
\text { перевал }\end{array}$ & 2380 & $1950-88$ & Норашеник & 1058 & $1953-64 *$ \\
\hline Сисиан & 1580 & $1913-17,1931-2018$ & Арцваник & 1320 & $1932-65 *$ \\
\hline Нораван & 1720 & $1958-64 *$ & Гехи & 1558 & 1948-51; 1952-88* \\
\hline Горис & 1398 & $\begin{array}{c}\text { 1913, 1915-17; } \\
\text { 1924- } 2018 \\
\end{array}$ & Бех & 1190 & $1932-64 *$ \\
\hline Горис ГМС & 1398 & $1952-86$ & Капан & 704 & $1933-2018(1938 ; 99)$ \\
\hline Ашотаван & 1695 & $1978-94 *$ & Каджаран & 1980 & $\begin{array}{c}1933-1973 * ; \\
1974-2018(1976)\end{array}$ \\
\hline Воротан & 1580 & 1953-2001* & Калер & 2000 & $1934-42,45-62 *$ \\
\hline Лцен & 1590 & $1936-82 *$ & Личк & 1769 & 1934-2001* \\
\hline Дарбас & 1516 & $1932-75^{*}$ & Шванидзор & 640 & $1932-2001 *$ \\
\hline Гаржис & 1489 & $1933-47 *$ & Нювади & 600 & $1949-62 *$ \\
\hline $\begin{array}{l}\text { ВоротанТатев } \\
\text { ГЭС }\end{array}$ & 705 & $1953-91 *(1968)$ & Мегри & 627 & 1930- 2018 \\
\hline
\end{tabular}

имеющей энергозатратную экономику и значительную зависимость от внешних поступлений энергоносителей.

Режим скорости ветра над территорией Армении и изучаемого региона, очень мало изучен. Определенный вклад в изучение режима скорости ветра внесли А. Б. Багдасарян [1], А. Г. Нерсесян [3]. Однако, в Армении специальных научных работ по изучению режима скорости ветра до сих пор не было. Публикации А.Б. Багдасаряна и А. Г. Нерсесяна относятся к 60-м годам ХХ века. Данные о ветровом режиме юго-восточной части Армении, приведены в ряде климатических пособий $[2,4]$. В справочнике [2] освещается ветровой режим территории Армении за период с 1936 по 1963 год. И только в работе [2] средние многолетние характеристики ветра были уточнены с использованием данных за период с 1936 по 2010 год. По объему материала и степени анализа гидрометеорологических условий все эти работы являются основными климатическими пособиями для Сюникского марза.
Целью настоящего исследования является оценка особенностей основных характеристик приземного ветра, анализ территориального распределения скорости ветра, уточнение распределения внутригодового хода и тенденция межгодового изменения скорости ветра на территории Сюникского марза Республики Армения. Приведена характеристика сильных ветров и штилей на территории Сюникского марза.

\section{МАТЕРИАЛЫ И МЕТОДЫ ИССЛЕДОВАНИЯ}

В качестве исходных данных в работе использованы материалы многолетних наблюдений за характеристикой скорости ветра со дня открытия станции до 2018 года (данные «Службы по гидрометеорологии и активному воздействию на атмосферные явления» МЧС Республики Армения). Отметим, что за время существования метеослужбы изменилось количество наблюдательных пунктов. Так, на изучаемой территории в разные годы действовали 32 пункта, из них 7 метеорологических станций, а в настоящее время действуют всего 5 метеорологических станций (таблица 1). Исход- 
Месячные (январь, апрель, июль, октябрь) и годовые значения средней скорости ветра (м/сек) по срокам наблюдений

[Table 2. Monthly (January, April, July, October) and annual values of average wind speed (m/s) by observation time]

\begin{tabular}{|c|c|c|c|c|c|c|c|c|c|}
\hline \multirow{2}{*}{$\begin{array}{l}\text { Метеорологические } \\
\text { станции / } \\
\text { Meteorological } \\
\text { stations }\end{array}$} & \multirow[b]{2}{*}{$\begin{array}{c}\text { Период } \\
\text { Period }\end{array}$} & \multicolumn{8}{|c|}{ Сроки / The timing } \\
\hline & & $00^{00}$ & $03^{00}$ & $06^{00}$ & $09^{00}$ & $12^{00}$ & $15^{00}$ & $18^{00}$ & $21^{00}$ \\
\hline \multirow{5}{*}{ Горис } & январь & 1,7 & 1,8 & 1,8 & 1,6 & 1,9 & 2,0 & 1,7 & 1,7 \\
\hline & апрель & 1,2 & 1,3 & 1,3 & 1,5 & 1,9 & 2,0 & 1,5 & 1,1 \\
\hline & июль & 1,0 & 1,0 & 1,0 & 1,2 & 1,6 & 1,7 & 1,1 & 1,0 \\
\hline & октябрь & 1,1 & 1,2 & 1,2 & 1,2 & 1,7 & 1,6 & 1,0 & 1,0 \\
\hline & год & 1,3 & 1,3 & 1,3 & 1,4 & 1,8 & 1,8 & 1,3 & 1,2 \\
\hline \multirow{5}{*}{ Капан } & январь & 0,7 & 0,9 & 0,9 & 0,8 & 1,6 & 2,3 & 1,2 & 0,9 \\
\hline & апрель & 0,7 & 0,7 & 0,7 & 1,3 & 2,9 & 3,5 & 2,4 & 1,1 \\
\hline & июль & 0,6 & 0,5 & 0,5 & 1,4 & 2,6 & 2,7 & 2,0 & 1,0 \\
\hline & октябрь & 0,6 & 0,6 & 0,6 & 0,8 & 2,2 & 2,7 & 1,4 & 0,8 \\
\hline & год & 0,7 & 0,7 & 0,7 & 1,1 & 2,3 & 2,8 & 1,7 & 1,0 \\
\hline \multirow{5}{*}{ Мегри } & январь & 1,2 & 1,2 & 1,3 & 1,2 & 1,6 & 1,6 & 1,2 & 1,1 \\
\hline & апрель & 0,8 & 0,8 & 0,8 & 1,2 & 2,2 & 2,1 & 1,7 & 1,2 \\
\hline & июль & 1,1 & 1,0 & 0,8 & 1,1 & 2,4 & 2,5 & 2,5 & 1,3 \\
\hline & октябрь & 0,5 & 0,8 & 0,5 & 0,7 & 1,4 & 1,6 & 1,3 & 1,0 \\
\hline & год & 1,2 & 1,2 & 1,3 & 1,2 & 1,6 & 1,6 & 1,2 & 1,1 \\
\hline
\end{tabular}

ные метеоданные всех этих пунктов привлечены в изложенных в настоящей статье материалах. Дополнительно использованы данные горной труднодоступной метеорологической станции Воротанский перевал, расположенной на высоте 2387 м в отрогах западной части Зангезурского хребта на границе двух марзов.

Анализ качества исходных материалов и проверка однородности рядов осуществлены с помощью параметра Стьюдента. Неоднородность чаще всего возникает из-за переноса флюгера, смены датчиков измерений, застройки вблизи станции жилыми или промышленными объектами, вырубки деревьев, близости крупных насаждений деревьев, а также из-за смены наблюдателей. Важным также является географическое положение самой станции.

Выбрали в качестве региона Сюникский марз потому, что анализ ряда источников позволяет сделать вывод о том, что этот марз имеет достаточный для использования потенциал ресурсов ветровой энергии.Так, среднегодовая скорость ветра в марзе Сюник составляет от 1,1 до 7,7 м/с.

B работе применялись методы математической статистики, GLIWARE. Статистическая обработка данных проводилась с помощью пакетов Statistica и Excel.

Сюникский марз расположен в юго-восточной части Армении. По размеру территории (4506 км²) марз занимает второе место в Армении, на его долю приходится $15 \%$ всей территории республики. Это самая гористая часть Армении. На западе от Амулсара до ущелья реки Аракс тянется Зангезурский хребет.

\section{РЕЗУЛЬТАТЫ И ОБСУЖДЕНИЕ}

Ветровой режим на изучаемой территории формируется под влиянием циркуляционных факторов климата. Так, с октября по апрель на Армянском нагорье образуется поле высокого давления, которое является одним из основных факторов зимнего режима ветра. В теплое время года на юге Закавказья формируется поле низкого давления, которое является одним из основных факторов летнего режима ветра [3]. Горные массивы - барьеры на пути продвижения воздушных масс и значительно изменяют характер циркуляции нижних слоев тропосферы, что влияет на гидротермические свойства воздушных масс. Ввиду большой пересеченности рельефа Армении, общее направление воздушных потоков заметно изменяется. Особенно ярко это проявляется в пестроте направления ветра в различных частях республики [1].

Основная характеристика ветра для его использования в получении ветровой энергии является его средняя скорость за определенный период времени. Проведенные исследования свидетельствуют, что на территории Сюника хорошо выражен 
Среднемесячная и годовая скорость (м/сек) ветра в марзе Сюник за период 1966-2018 гг.

$$
(* *-1975-2018, *-1966-1988)
$$

[Table 3. Average monthly and annual wind speed $(\mathrm{m} / \mathrm{s})$ in the Syunik marz area for the period 1966-2018 $(* *-1975-2018, *-1966-1988)]$

\begin{tabular}{|l|c|c|c|c|c|c|c|c|c|c|c|c|c|}
\hline $\begin{array}{l}\text { Метеорологические } \\
\text { станции / } \\
\begin{array}{l}\text { Meteorological } \\
\text { stations }\end{array}\end{array}$ & I & II & III & IV & V & VI & VII & VIII & IX & X & XI & XII & $\begin{array}{l}\text { Год / } \\
\text { Year }\end{array}$ \\
\hline Воротанский перевал & 3,97 & 4,12 & 4,28 & 4,42 & 4,61 & 5,49 & 6,83 & 6,65 & 5,09 & 4.10 & 3.74 & 3.90 & 4.77 \\
\hline Сисианский перевал* & 8,52 & 8,15 & 8,11 & 7,45 & 6,63 & 7,05 & 8,49 & 9,05 & 7,16 & 6,58 & 7,29 & 8,28 & 7,71 \\
\hline Сисиан & 1,50 & 1,58 & 1,72 & 1,59 & 1,50 & 1,91 & 2,48 & 2,53 & 1,88 & 1,24 & 1,22 & 1,37 & 1,71 \\
\hline Горис & 1,69 & 1,50 & 1,38 & 1,40 & 1,20 & 1,21 & 1,19 & 1,15 & 1,13 & 1,19 & 1,38 & 1,70 & 1,35 \\
\hline Капан & 1,13 & 1,32 & 1,49 & 1,57 & 1,44 & 1,39 & 1,37 & 1,37 & 1,24 & 1,20 & 1,12 & 1,05 & 1,29 \\
\hline Каджаран** & 1,19 & 1,13 & 1,21 & 1,25 & 1,24 & 1,24 & 1,27 & 1,17 & 1,05 & 0,98 & 0,95 & 1,14 & 1,16 \\
\hline Мегри & 1,06 & 1,14 & 1,14 & 1,09 & 0,97 & 1,13 & 1,30 & 1,33 & 1,04 & 0,81 & 0,86 & 0,99 & 1,08 \\
\hline
\end{tabular}

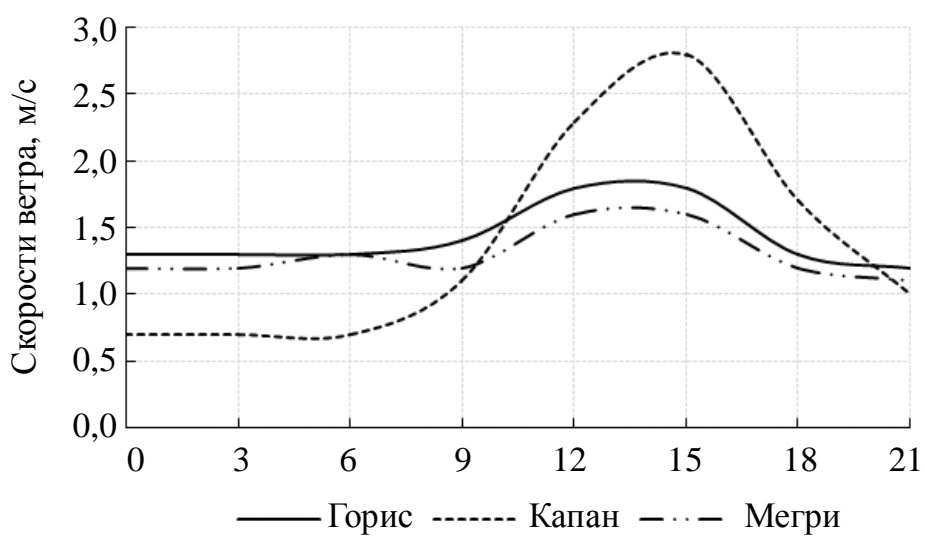

Puc. 1. Среднесрочные значения скорости ветра на метеостанциях Горис, Капан и Мегри [Fig. 1. Medium-term wind speeds at the Goris, Kapan and Meghri stations]

суточный ход скорости ветра (таблица 2). Причем, на протяжении всего года наибольшая скорость ветра отмечалась в полуденные часы ( $\left.15^{00} \mathrm{UTC}\right)$, что видно на примере (рис. 1) распределения скорости ветра по срокам за год по станции Горис, Капан и Мегри. Минимальные среднесрочные значения скорости ветра наблюдаются с $00^{00}$ по $09^{00}$ UTC. Для января в районе станции Горис и Мегри характерен небольшой суточный ход: скорости ветра изменяются соответственно в пределах от 1,7 до 2,0 м/с и от 1,1-1,2 до $1,6 \mathrm{M} / \mathrm{c} \mathrm{в} 00^{00}$ и $15^{00}$ UTC. Это можно объяснить доминированием циклонической циркуляции зимой над изучаемой территории. Таким образом, в Сюникском марзе скорость ветра в течение суток растет в дневное время и максимум в теплое, послеобеденное время, а начиная с полуночи до раннего утра, скорость ветра снижается и достигает минимума.

В таблице 3 представлены многолетние среднемесячные и годовые значения скорости ветра за период 1966-2018 годов, согласно фактическим наблюдениям действующих в настоящее время метеорологических станций. В виде исключения приводятся также фактические данные Сисианского перевала, несмотря на то, что последний закрыт с ноября 1988 года. Причина в том, что на этой метеорологической станции зарегистрировано максимальное значение среднемесячного и среднегодового ветра не только на изучаемой территории, но и на всей территории республики.

Из таблицы видно, что средняя годовая скорость ветра на исследуемой территории колеблется от 1,1 до 7,7 м/сек. Из 7-и метеорологических станций наибольшие средние скорости ветра наблюдаются на Сисианском и Воротанском перевалах, особенно летом. Это объясняется факторами, влияющими на скорость ветра. Так, большим скоростям ветра на Сисианском перевале способствует положение перевала: он открыт с востока и запада, а с севера и юга закрыт горами. С восточной 


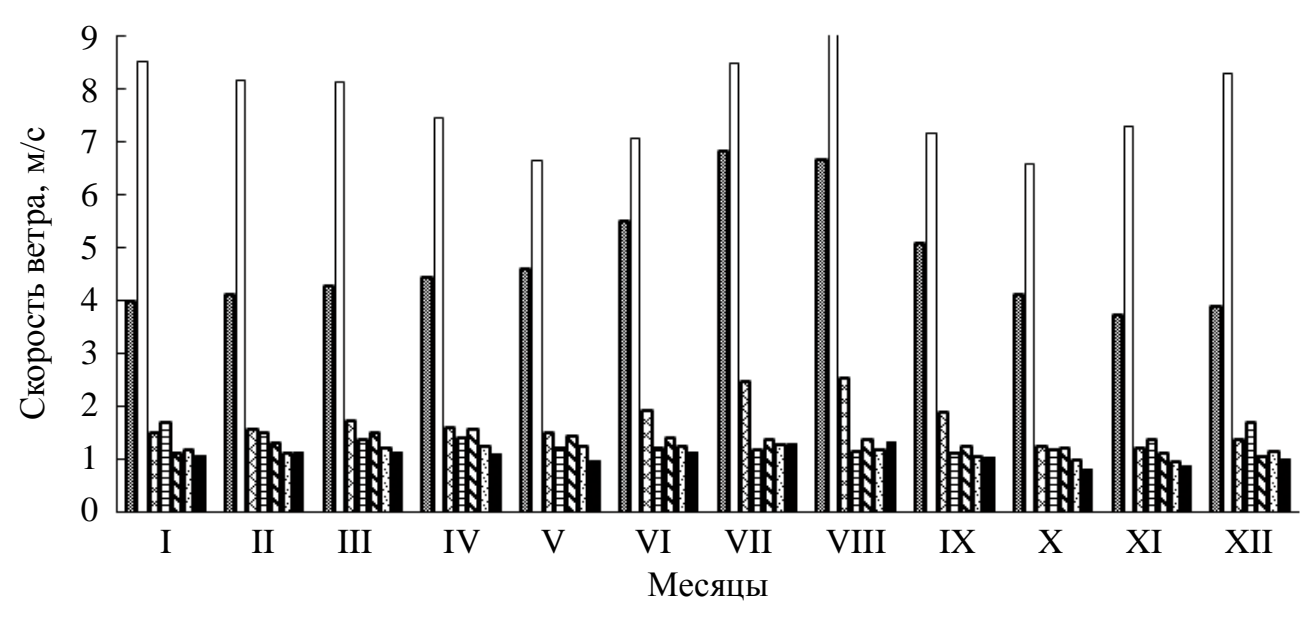

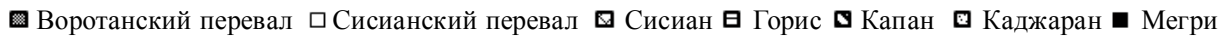

Puc. 2. Гододвой ход скорости (м/сек) ветра в марзе Сюник

[Fig. 2. Annual course of wind speed $(\mathrm{m} / \mathrm{s})$ in the Syunik marz area]

стороны перевал направлен к Воротанскому бассейну, где зимы холодные, лето умеренно жаркое, с западной стороны перевал направлен в сторону Нахичеванского бассейна, где лето жаркое, зима теплая. В западной и восточной частях заметно различие температур воздуха, а значит и давления воздуха, что способствует усилению ветра. Наименьшие средние скорости ветра наблюдаются в Мегри, особенно осенью и зимой. Это обусловлено тем, что он расположен между южными склонами горных хребтов Мегри и Зангезур, в глубоком ущелье реки Мегри на высоте 627 метров.

Согласно многолетним средним данным о скорости ветра на исследуемой территории его годовой ход выражается не совсем ясно. Средние месячные скорости ветра по рассматриваемым станциям Сюник представлены на рисунке 2. Рисунок позволяет оценить амплитуды пространственных и сезонных изменений средней скорости ветра в марзе Сюник.

Годовой ход распределения средней скорости ветра отличается неоднозначными закономерностями. Он четко выражается только на метеорологической станции Воротанский перевал, где в течение года наблюдается одно максимальное (июль) и одно минимальное (ноябрь) значение. На некоторых метеорологических станциях (Сисианский перевал, Сисиан, Каджаран и Мегри) наблюдаются два максимальных и минимальных значения скорости ветра. Так, в Сисиане и Мегри первый минимум отмечается в мае, второй минимум (который является главным) - в октябре-ноябре, а максимум приходится, соответственно, на март и август. Период регистрации минимума на Сисианс- ком перевале совпадает, а максимум наблюдается в декабре-январе и августе. В Каджаране минимум регистрируется в феврале и ноябре, а максимум декабре-январе и июле. Годовой ход скорости ветра в Горисе и Капане не ясен. В Горисе происходит рост средней скорости ветра с октября по январь, а потом уменьшается. В Капане наблюдается рост средней скорости ветра с января по апрель, а затем происходит понижение.

Таким образом, в Сюникском марзе наблюдаются два типа годового распределения скорости ветра: простой (один максимальный и один минимальный) и сложный (два максимальных и два минимальных). При этом, главная максимальная скорость ветра наблюдается летом, главный минимум - осенью. Летом диапазон значений средней скорости ветра изменяется от 1,13 м/с до 9,05 м/с, осенью скорость ветра уменьшается до $6,58 \mathrm{M} / \mathrm{c}$ и 0,81 м/с соответственно. Исключение составляют станции Горис и Капан. Максимальная скорость ветра в Горисе наблюдается в декабре-январе, в Капане - в апреле, а минимальная скорость, соответственно, в мае-октябре и ноябре-январе.

Как правило, с высотой растет скорость ветра. Получена корреляционная связь между годовыми средними значениями скорости ветра исследуемой территории и высотой места (рис. 3) согласно фактическим данным 5 метеорологических станций (1966-2018 гг.). Данные метеорологических станций Каджаран и Сисиан не использовались для сохранения ряда наблюдений из-за однородности. Этой связи можно использовать для изучения режима скорости ветра неизученных и мало изученных территорий Сюникского марзы. 
Повторяемость скорости ветра (дни) для станции Каджаран по градациям за январь и июль, период 2000-2018 годы

[Table 4. Wind speed repeatability (days) for the Kajaran station according to gradations for January and July for the period 2000-2018]

\begin{tabular}{|l|c|c|c|c|c|}
\hline \multirow{2}{*}{$\begin{array}{c}\text { Mесяцы / } \\
\text { Months }\end{array}$} & \multicolumn{5}{|c|}{$\begin{array}{c}\text { Повторяемость скорости ветра (дни) / } \\
\text { Repeatability of wind speed (days) }\end{array}$} \\
\cline { 2 - 6 } & $0-1$ & $1-2$ & $2-4$ & $4-9$ & $9-12$ \\
\hline Январь & 21,1 & 6,4 & 2,7 & 0,8 & 0 \\
\hline Июль & 16,8 & 11,3 & 2,8 & 0,1 & 0 \\
\hline
\end{tabular}

Более подробную характеристику ветрового режима можно получить по данным о вероятности различных скоростей ветра. В таблице 4 представлены данные повторяемости скоростей ветра для станции Каджаран за январь и июль. В зависимости от сезона эти величины значительно изменяются. Так, в среднем за январь по территории в $88 \%$ случаев наблюдается слабый ветер (до 2 м/с). Большой процент составляют ветры со скоростью 01 м/с (68\%). А за июль в среднем в $90 \%$ случаев наблюдается слабый ветер (до 2 м/с). Причем, со скоростью 0-1 м/с ветры составляют $54 \%$, а со скоростью 1-2 м/с ветры - 36\%. За январь и июль в среднем 8-9\% случаев приходится на скорость ветра от 2 до 4 м/с. Ветер со скоростью 4-9 м/с повторяется соответственно в 2,6 и 0,3\% случаев. Скорости ветра $\geq 10$ м/с составляют 0 случаев. Как правило, с увеличением скорости ветра снижается его частота.

На рисунке 4 показаны гистограммы повторяемости штилей и максимальные скорости ветра по месяцам и за год. Гистограммы позволяют представить распределение скоростей ветра по сезонам года. Видно, что наибольшее значение повторяемости штилей (53-55\%) за год отмечается в Сисиане, Каджаране и Мегри, наименьшее значение повторяемости (5-12\%) - на Сисианском перевале и Воротанском перевале. Это объясняется особенно географическим положением метеорологической станции, степенью закрытости горизонта.

В марзе Сюник максимальная годовая скорость ветра колеблется в пределах от 18 м/с (Сисиан, Капан) до 48 м/с (Сисианский перевал).

В условиях глобального изменения климата актуальность проблемы изменений ветрового режима значительно возросла. По этой причине в настоящей статье нами были также рассмотрены вопросы динамики изменения скорости ветра на изучаемой территории. Несмотря на то, что длина некоторых рядов достигает 100-106 лет, с целью унификации статистического анализа и сравнимо-



Puc. 3. Среднегодовые значения скорости ветра и корреляционная связь между высотой места

[Fig. 3. Annual average wind speed and correlation between place height]

сти трендов, при расчетах использовали ряды продолжительностью 53 года (1966-2018 гг.). Аналогичные расчеты были проведены и для полных рядов. В результате исследований выяснилось, что динамику изменения скорости ветра для Сюникского марзы нельзя представлять одной линией тренда. Поэтому для оценки динамики изменения скорости ветра были выделены три периода: 1) 1966-1985; 2) 1986-2000; 3) 2001-2018 годы.

Анализ показывает, что, как по месяцам, так и за год наблюдается неоднородная динамика изменения средних значений скорости ветра. Так, на Воротанском перевале и в Капане за все месяцы и за год (период 1986-2010) наблюдается рост средней скорости ветра по сравнению с периодом за 1966-1985 годы, а в Сисиане и Мегри - наоборот, понижение. В Горисе с декабря по апрель происходит понижение, а далее - рост, в том числе и среднегодовых значений. Что касается тенденции изменения средних значений ветра за период с 2011-2018 годы по сравнению с периодом за 19862010 годы, то она имеет следующий вид: в Капане 


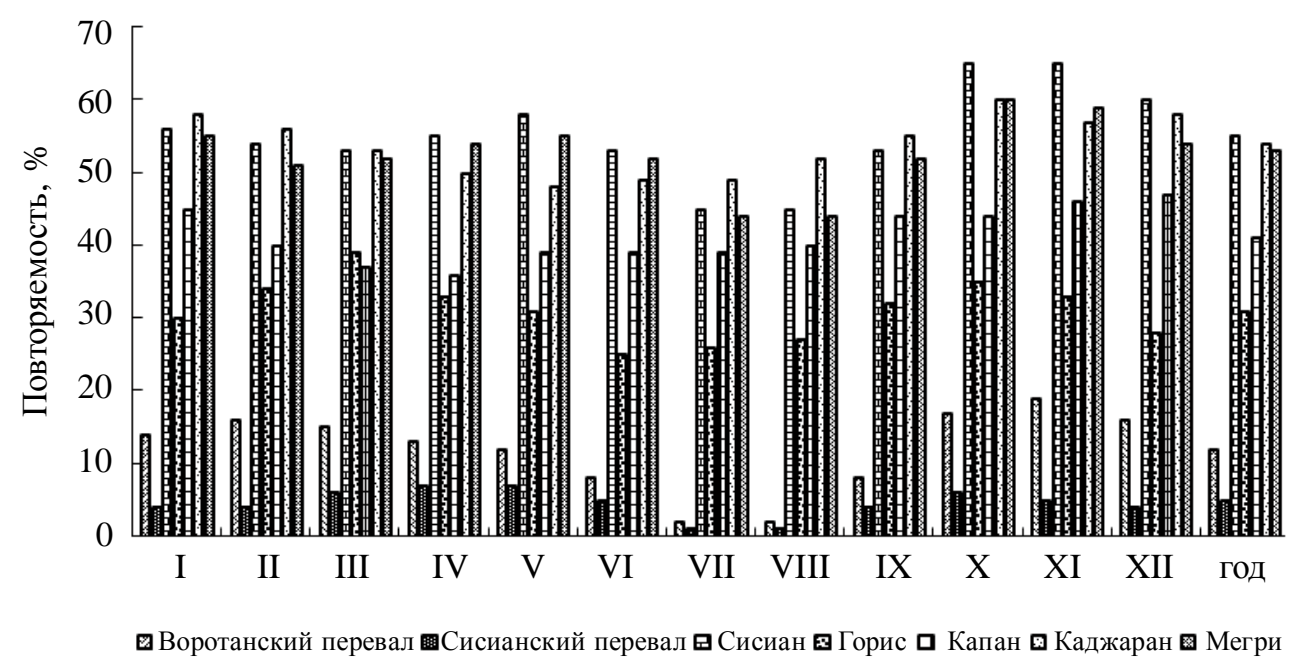

(a)



(б)

Puc. 4. Гистограммы повторяемости штилей (а) и максимальные скорости ветра (б) в марзе Сюник [Fig. 4. Histograms of repeatability of calms (a) and maximum wind speeds (b) in the Syunik marz area]

однозначно тенденция понижения, а в Мегри - тенденция роста. На других метеорологических станциях (Воротанский перевал, Сисиан, Горис) сохраняется тенденция и роста, и понижения. То есть, динамика изменения скорости ветра в условиях гор имеет сложный и разнообразный вид, поскольку там кроме воздействия изменения климата на режим ветра, большое влияние имеет также орография. Однако, в общем, как закономерность, за исключением периодов с января по апрель и с июля по сентябрь, в марзе с 1986-2010 годы наблюдается тенденция уменьшения скорости ветра по сравнению с периодом за 1966-1985 годы, а в 20112018 годы, по сравнению с периодом за 1986-
2010 годы, за исключением марта месяца, - тенденция уменьшения.

\section{ВЫВОДЫ И РЕКОМЕНДАЦИИ}

В результате исследований сделаны следующие выводы.

1. На территории Сюникского марза хорошо выражен суточный ход скорости ветра: скорость ветра в течение дня растет в дневное время и максимум в теплое, послеобеденное время, а, начиная с полуночи до раннего утра, скорость ветра снижается и достигает минимума.

2. Средняя годовая скорость ветра на исследуемой территории колеблется от 1,1 до 7,7 м/сек. Причем, наибольшие средние скорости ветра на- 
блюдаются на Сисианском и Воротанском перевалах (от 4,8 м/с до 7,7 м/с), особенно летом. В других местах изучаемой территории скорости ветра невелики. Они изменяются от 1,1 м/с до 1,7 м/с.

3. В Сюнике в условиях пересеченной местности на распределение годового хода скорости ветра большое влияние оказывает рельеф. Поэтому здесь наблюдается разнообразие годового хода скорости ветра.

4. Годовой ход скорости ветра отличается неоднозначными закономерностями: наблюдается два типа годового распределения скорости ветра: простой (один максимальный и один минимальный) и сложный (два максимальных и два минимальных).

5. Получена корреляционная связь между годовыми средними значениями скорости ветра исследуемой территории и высотой места. С высотой растет скорость ветра.

6. Повторяемость штилей в среднем по территории составляет приблизительно от 5-12 до 53-55\%.

7. Максимальная годовая скорость ветра колеблется в пределах от 18 м/сек (Сисиан, Капан) до 48 м/сек (Сисианскый перевал). Максимальные значения ветра также наблюдаются на Сисианском перевале.

8. Как закономерность, за исключением периодов с января по апрель и с июля по сентябрь, в марзе с 1986-2010 годы наблюдается тенденция уменьшения скорости ветра по сравнению с периодом за 1966-1985 годы, а в 2011-2018 годы, по сравнению с периодом за 1986-2010 годы, за исключением марта месяца, - тенденция уменьшения.

9. Изменения скорости ветра являются местным проявлением изменения процессов глобальной циркуляции, поэтому необходимо использовать его как индикатор изменения климата.

10. Полученные результаты могут быть использованы при планировании развития ветроэнергетики на территории Сюникского марза с учетом тенденции вековых изменений скорости ветра.

\section{СПИСОК ЛИТЕРАТУРЫ}

1. Багдасарян А. Б. Климат Армянской ССР. Ереван, Изд-во АН АрмССР, 1958. 146 с.

2. Климатический справочник. Часть III. Атмосферное давление и Ветер. Ереван, 2013. 160 с. (на армянском языке). $304 \mathrm{c}$.

3. Нерсесян А.Г. Климат Армении. Ереван, 1964.

4. Справочник по климату СССР. Ч. III. Ветер, вып. 16. Ленинград, Гидрометеоиздат, 1967. 168 с.

Конфликт интересов: Автор декларирует отсутствие явных и потенциальных конфликтов интересов, связанных с публикацией настоящей статьи.

Поступила в редакциию 25.02.2020 Принята к публикации 02.06.2020

\title{
Features of the Regime of Wind Speed Climatic Characteristics in the Syunik Marz Area
}

\author{
V.G. Margaryan ${ }^{\bowtie}$ \\ Yerevan State University, Armenia (1, Alek Manoukian St., Yerevan, 0025)
}

\begin{abstract}
The purpose is to study the features of the regime of climatic characteristics of wind speed in the Syunik marz area of the Republic of Armenia is an urgent task, especially in connection with the fact that the Armenian economy significantly dependent on external energy inputs. And wind power can be used as a source of alternative energy.

The article analyzes and evaluates the patterns of the regime of wind speed, their territorial and temporal distribution, daily and intra-year course, the trend of interannual changes in the study area. Also the characteristic of strong winds and calms is given. For analysis, we used the data of the Hydrometservice of the Republic of Armenia for a period of 50 years and more (1966-2018) at 7 weather stations.
\end{abstract}

(c) Margaryan V.G., 2020

E-mail: vmargaryan@ysu.am

The content is available under Creative Commons Attribution 4.0 License. 


\section{V.G. Margaryan}

It was revealed that a well-defined diurnal and varied annual course is observed in the Syunik marz area. The diversity of the annual course of wind speed due to the terrain. Average annual rate wind is 1.1-7.7 m/s, and the annual maximum wind speed is $18-48 \mathrm{~m} / \mathrm{s}$. The highest wind speeds are observed at the Sisian and Vorotan passes. With height, wind speed rises. The correlation between the annual average wind speed in the studied area and the height of the place has been revealed. The values can be used to study the wind speed regime of unexplored and little studied areas. In the marz for the period 2011-2018 basically, there is a tendency for a decrease in wind speed compared to the period from 1966-1985. The analysis of the spatial variation of the wind speed regime characteristics showed a diversity due to the ruggedness terrain where the terrain has a large impact on the distribution wind speed characteristics.

The results can be used in planning the development of wind energy in the Syunik marz area, the development of wind energy cadastres of areas, climate services for sectors of the economy, adjustment of building standards.

Key words: Armenia, Syunik marz, wind speed, repeatability, calm, global climate change, deviations.

For citation: Margaryan V.G. Features of the Regime of Wind Speed Climatic Characteristics in the Syunik Marz Area. Vestnik Voronezskogo gosudarstvennogo universiteta. Seria Geografia. Geoekologia, 2020, No. 2, pp. 46-54. (in Russ.) DOI: https://doi.org/10.17308/geo.2020.2/2885

\section{REFERENCES}

1. Baghdasaryan A. B. Klimat Armyanskoj SSR [The climate of Armenian SSR]. Yerevan, Publ. House of the Armenian SSR Academy of Sciences, 1958. 151 p. (In Russ.)

2. Klimaticheskiy spravochnik [Climate guide]. Part 3. Atmospheric pressure and wind. Yerevan, 2013. 160 p. (in Armenian)

\section{Маргарян Вардуи Гургеновна}

кандидат географических наук, доцент кафедры физической географии и гидрометеорологии географического и геологического факультета Ереванского государственного университета, г. Ереван, Республика Армения, ORCID: https://orcid.org/0000-0003-3498-0564, e-mail:vmargaryan@ysu.am
3. Nersesyan A. G. Klimat Armenii [Climate of Armenia]. Yerevan, 1964. 304 p. (in Armenian)

4. Spravochnik po klimatu SSSR [USSR climate guide], issue 16, part 3. Wind. Leningrad, Hydromet publ., 1967. 168 p. (in Russ.)

Conflict of interests: The author declares no information of obvious and potential conflicts of interest related to the publication of this article.

Received: 25.02 .2020

Accepted: 02.06.2020

Vardui G. Margaryan

Cand. Sci. (Geogr.) Assoc. Prof. of the Department of physical geography and hydrometeorology of the Geographical and Geological Faculty, Yerevan State University, Yerevan, Armenia, ORCID: https://orcid.org/0000-0003-3498-0564, e-mail: vmargaryan@ysu.am 